\title{
Skin Characteristics of Sites Predisposed to Pressure Ulcers among Bedridden Elderly Patients in Japan
}

\author{
Hiroko Takeshima Kohara1, Mitsunori Ikeda1', Kunihiko Yokotani², Masami Okawa², \\ Sanae Nishimoto ${ }^{2}$
}

${ }^{1}$ Department of Nursing, University of Kochi, Kochi, Japan

${ }^{2}$ Shiragikuen Hospital, Tosa, Kochi, Japan

Email: hkohara@cc.u-kochi.ac.jp

How to cite this paper: Kohara, H.T., Ikeda, M., Yokotani, K., Okawa, M. and Nishimoto, S. (2021) Skin Characteristics of Sites Predisposed to Pressure Ulcers among Bedridden Elderly Patients in Japan. Open Journal of Nursing, 11, 497-512.

https://doi.org/10.4236/ojn.2021.116043

Received: May 25, 2021

Accepted: June 21, 2021

Published: June 24, 2021

Copyright $\odot 2021$ by author(s) and Scientific Research Publishing Inc. This work is licensed under the Creative Commons Attribution International License (CC BY 4.0).

http://creativecommons.org/licenses/by/4.0/

\begin{abstract}
Background: Previous studies have not specifically measured skin characteristics at common sites of pressure ulcers in high-risk elderly patients. Therefore, this study aimed to clarify the physiological skin characteristics at common pressure ulcer sites and their relationship with pressure ulcer risk and demographic/laboratory data in bedridden elderly Japanese patients. Methods: This study involved 55 elderly Japanese patients in a long-term care hospital and 25 female Japanese university students. Skin surface temperature, epidermal water content, transepidermal water loss, skin erythe$\mathrm{ma} /$ redness, skin elasticity, and skin thickness were measured using noninvasive devices. The sacral and both heel areas (sites predisposed to pressure ulcers) and mid-to-lower back area (control site) were observed. Results: Elderly patients showed a low epidermal water content at both heels (right heel, $14.8 \pm 9.1$ arbitrary units, AU.; left heel, $14.4 \pm 8.3 \mathrm{AU}$ ). Transepidermal water loss remained acceptable at all sites in older patients despite the presence of dry skin (back, $7.1 \pm 1.8 \mathrm{~g} / \mathrm{hm}^{2}$; sacrum, $7.4 \pm 3.0 \mathrm{~g} / \mathrm{hm}^{2}$; right heel, $17.7 \pm$ $7.1 \mathrm{~g} / \mathrm{hm}^{2}$; left heel, $\left.19.4 \pm 8.1 \mathrm{~g} / \mathrm{hm}^{2}\right)$. Back $(0.61 \pm 0.13 \mathrm{AU})$ and sacral $(0.67$ $\pm 0.11 \mathrm{AU})$ skin elasticity and sacral skin thickness $(0.97 \pm 0.56 \mathrm{~cm})$ were significantly lower than those of healthy young people $(0.86 \pm 0.04 \mathrm{AU}, 0.87 \pm$ $0.05 \mathrm{AU}$, and $2.27 \pm 0.84 \mathrm{~cm}$, respectively; $p<0.001$ for all sites). Moderate positive correlations were observed between back skin elasticity and serum albumin level $(\mathrm{r}=0.445, p<0.001)$, and between sacral skin thickness and BMI $(r=0.506, p<0.001)$ in older patients. Conclusions: Our findings showed that skin thickness and elasticity should be prioritized when evaluating pressure ulcer risk at the sacral region in bedridden elderly Japanese patients. Moreover, skin moisturization should be considered to minimize the risk at the heels in such patients.
\end{abstract}




\section{Keywords}

Epidermal Water Content, Pressure Ulcer, Skin Barrier Function, Skin Elasticity, Skin Erythema, Skin Surface Temperature, Skin Thickness

\section{Introduction}

As suggested by VanGilder et al. [1], prevalence rates of pressure ulcers across all facilities within the United States have decreased from 13.5\% in 2006 to $9.3 \%$ in 2015. Meanwhile, prevalence rates in medical facilities across Japan had been estimated to range from $0.96 \%$ to $8.32 \%$ in 2006 [2] and $0.77 \%$ to $2.81 \%$ in 2016 [3]. Despite the declining prevalence rates, occurrences of pressure ulcers in elderly patients above 65 years old remain a challenge [3]. Moreover, increased treatment costs [4] and lower quality of life [5] due to pressure ulcers have remained important public health issues. A previous survey conducted in a Japanese rural area in 2016 revealed that most patients with pressure ulcers were older and had age-related diseases and malnutrition [6]. As such, elderly patients should receive not only proper pressure ulcer risk assessment but also appropriate prophylactic care.

Elderly individuals tend to have vulnerable skin due to physical changes associated with aging, such as thinning of dermal and subcutaneous tissues and reduced resiliency and elasticity [7] [8] [9]. Owing to morphological and physiological changes, external forces applied to the skin surface can easily be transmitted to underlying tissues, resulting in tissue distortion and ischemia [10]. The decrease in the number of sweat and sebaceous glands associated with decreased activity promotes reduced sweat and sebum production, subsequently leading to increased skin surface $\mathrm{pH}$ [11]. This phenomenon decreases skin barrier function, causing vulnerability to bacterial pathogens [11]. Thus, elderly individuals with urinary and fecal incontinence are prone to developing dermatitis due to increased skin surface $\mathrm{pH}$, dry skin, and decreased immune function [12]. Prolonged contact with urine and feces can also increase the water content within the stratum corneum, which increases the susceptibility of the macerated skin to pathogens, irritants, and enzymes [10]. Such damages to the skin contribute to pressure ulcer formation due to increased friction and shear forces [10].

The skin condition may be measured by skin physiological indices using noninvasive devices. Previous studies have assessed several skin physiological indices, including surface temperature [13] [14], barrier function [13] [15] [16] [17] [18], elasticity [15] [16] [19], color [13] [16] [19], and thickness [20], across various sites in subjects of various ages. These values, however, had been measured on skin covering uncommon pressure ulcer sites [13] [16], in only the sacral region [18], and young or middle-aged adults [14] [17] [19] [20] or relatively well-nourished elderly patients [15]. Although pressure ulcer prevention based on the skin condition is important in elderly patients, insufficient research has 
been available regarding skin physiological indices at common pressure ulcer sites in actual bedridden elderly patients.

Therefore, the present study aimed to clarify the physiological skin characteristics at common pressure ulcer sites in elderly Japanese patients at high risk for pressure ulcers. To this end, physiological skin indices at common pressure ulcer sites in bedridden elderly Japanese patients were compared to those in healthy Japanese young adults, after which relationships between skin physiological indices and demographic/laboratory data were examined in elderly Japanese patients.

\section{Subjects and Methods}

A cross-sectional study was conducted on elderly Japanese patients admitted in a long-term care hospital and university students between October 2017 and August 2018 in Japan.

\subsection{Subjects}

A total of 55 elderly patients and 25 healthy young adults were recruited. The long-term care hospital was equipped with 200 beds and provided care to rural residents of Kochi prefecture, Japan. This facility provides care aimed at preventing pressure ulcers in accordance with the facility's policy consisting of guidelines for skin and continence care, regular turning and repositioning of the supporting surface mat on the bed to reduce pressure, and consultation with a nutritionist for bedridden patients. Healthy young adults comprised female Japanese university students in their 20s who were recruited via the network of researchers. Both patients and controls were recruited during the study period.

\subsection{Inclusion/Exclusion Criteria}

Patients without skin disorders, aged $\geq 60$ years, and had a cumulative Braden Scale score $\leq 18$ as a high risk for pressure ulcers [21] were included. Those with a possibility of changes in physical conditions such as fluctuations of blood pressure were excluded to avoid physical stress associated with maintaining the same body position during the observation. Patients who satisfied the inclusion criteria were identified and recruited by hospital nurses unrelated to this study and trained on how to use the Braden Scale.

Healthy young adults not suffering from any disease, obesity and thinness requiring treatment, and skin disorders were included.

\subsection{Ethical Approval}

The study's procedures were approved by the research ethics committees of the facility and participating institution (University of Kochi, Approval Number: 17-7 and 17-43) and adhered to the guidelines stipulated in the Declaration of Helsinki. All included participants or family members of those unable to provide consent involved in this study provided written informed consent. None of the 
authors have any conflicts of interest or financial ties to disclose.

\subsection{Procedures}

The following six items were measured from both elderly patients and healthy young adults: epidermal water content; transepidermal water loss (TEWL) measuring skin barrier function; and skin erythema, elasticity, surface temperature, and thickness. The abovementioned items were assessed over four areas, including the sacrum and both heels (i.e., sites predisposed to pressure ulcers) and the mid-to-lower back (e.g., the control site). Participants were placed in the lateral position, with the measurement sites being identified through manual palpation. The authors confirmed that no skin care products were applied before the measurements. Noninvasive devices were used to measure each item. To avoid any possible effects caused by devices touching the skin on the measured values, skin surface temperature was measured first, followed by skin erythema, epidermal water content, TEWL, skin elasticity, and skin thickness [19]. Room temperature and humidity were maintained at $22^{\circ} \mathrm{C}-24^{\circ} \mathrm{C}$ and $40 \%-50 \%$, respectively. Healthy young adults were housed in a room also kept at the same temperature and humidity ranges. The experiments were carried out in the afternoon to avoid any disturbance caused by the circadian rhythm. All participants underwent an adaptation period of at least $30 \mathrm{~min}$ before the measurements.

\subsection{Non-Invasive Devices}

Corneometer ${ }^{\circledR} \mathrm{CM} 825$ (Courage-Khazaka electronic GmbH, Cologne, Germany) was used to measure epidermal water content. Measurements are presented as 0 - 120 arbitrary units (AU) with a precision of $\pm 0.3 \%$ [22] [23]. Epidermal water content values of $<60$ and $<50 \mathrm{AU}$ in the upper body and legs indicate dryness, respectively. Epidermal water content values were measured four times per site and then averaged. Tewameter ${ }^{\mathbb{B}} \mathrm{TM} 300$ (Courage-Khazaka electronic GmbH) was used to measure transepidermal water loss. This device measures the amount of evaporated water content from the skin surface $\left(\mathrm{g} / \mathrm{hm}^{2}\right)$ [24]. Smaller TEWL values indicate better skin conditions, whereas values $\geq 25 \mathrm{~g} / \mathrm{hm}^{2}$ indicate poor skin conditions. Average TEWL values obtained by the device were recorded [25]. Mexameter ${ }^{\circledR}$ MX18 (Courage-Khazaka electronic GmbH) was used to measure skin erythema. This device measures the hemoglobin content in the skin. Erythema values are expressed in 0 - $999 \mathrm{AU}$, with precision of $\pm 0.5 \%$ [26] [27]. Skin erythema values of $0-170,170-330,330-450,450-570$, and $>570$ AU indicate no, minor, diffuse, high-degree, and extreme erythema, respectively. Skin erythema measurements were conducted four times per site and then averaged. Cutometer ${ }^{\circledR}$ MPA580 (Courage-Khazaka electronic $\mathrm{GmbH}$ ) was used to measure elasticity. This device has a $4-\mathrm{mm}$ diameter opening suction probe that pulls the target skin into the probe through a vacuum pressure, followed by a rest period. This cycle is repeated 10 times. Vertical skin deformation was then measured and analyzed using the computer software associated with Cutome- 
ter ${ }^{\circledR}$ MPA580. This device measures skin elasticity with its parameters ranging from R0 to R9. We have used R2 was used considering that it represents elasticity of the overall skin. Overall skin elasticity is expressed in 0 - $1.00 \mathrm{AU}$ [28] [29]. The closer the R2 value is to 1 , the higher the elasticity. Skin elasticity was measured three times per site and then averaged. THERMOFOCUS ${ }^{\circledR}$-PRO (Tecnimed Srl, Vedano Olona, Italy) was used for surface temperature measurement. This thermometer is a non-contact device with a measurement range of $1.0^{\circ} \mathrm{C}$ to $55.0^{\circ} \mathrm{C}$ and precision of $\pm 0.3^{\circ} \mathrm{C}$. Surface temperatures were measured four times per site and then averaged. Skin thickness was measured using a small-sized ultrasound imaging system, Vscan Dual Probe ${ }^{\circledR}$ (GE Healthcare, Tokyo, Japan), which has an electronic sector probe for observing deep areas and a high frequency linear contact for observing shallow areas. The image of the measured thickness is then displayed on a monitor. Skin thickness was determined by the depth between the surface of the highly echogenic cortical bone and the skin surface [20]. Skin thickness was measured in the longitudinal and lateral directions across three sites, including the sacrum and both buttocks, with the smallest measurement being used. All skin thickness measurements were made with the probe positioned perpendicular to the skin without compressing the subcutaneous tissue to ensure accurate thickness measurements [20].

\subsection{Pressure Ulcer Risk Variable}

Data related to pressure ulcer risk factors were collected from each patient's medical record and skin examination findings. The Braden Scale [30] was used to assess the patients' pressure ulcer risk. This scale consists of six subscales (sensory perception, activity, mobility, skin moisture, friction/shear, and nutrition) each scored between 1 and 4 (except for friction and shearing, which are scored up to 3) and totaled, with total scores ranging from 6 to 23 [30]. A cutoff score of $\leq 18$ indicates increased risk for pressure ulcer development [31]. The Mini Nutritional Assessment (MNA), which has been shown to be indirectly related to pressure ulcer occurrence among patients aged $\geq 65$ years, was used to assess patients' nutritional status [32] [33]. The MNA consists of six items on food intake, weight loss, mobility, psychological stress or acute disease, neuropsychological problems, and body mass index (BMI) or calf circumference. Based on the total score, nutritional status was categorized as follows: normal nutritional status $(12-14)$, at risk of malnutrition $(8-11)$, and malnourished $(0-7)$.

\subsection{Statistical Analysis}

Statistical analysis was performed using SPSS version 25 (IBM, Armonk, New York, USA). The Shapiro-Wilk test was used to determine the normality of data distribution for elderly patients and healthy young adults. The Mann-Whitney $U$ or independent $t$-test was then performed to compare skin physiological indices between groups as appropriate. Similarly, Pearson's or Spearman's rank correlation coefficient was utilized to examine the relationship between skin physiologi- 
cal indices and pressure ulcer risk in elderly patients. Two-tailed tests were used, with the significance set at $\mathrm{p}<0.05$. After completing this study, post-hoc power analysis was performed using $G^{*}$ Power 3 (Heinrich-Heine-Universität, Dusseldorf, Germany) [34], which calculates statistical power using significance level, effect size, and sample size [35]. Effect size was calculated using the degrees of freedom and the $\mathrm{t}$-value for independent $t$-tests and the $\mathrm{Z}$-value and number of subjects for the Mann-Whitney $U$ test.

\section{Results}

\subsection{Sample Characteristics}

A total of 55 elderly patients and 25 healthy young adults were eligible for study participation (Table 1). The medical data and pressure ulcer risk among elderly patients are summarized in Table 2. Accordingly, elderly patients had median Braden and MNA scores of 12.5 (interquartile range, 9.0 - 15.0) and 8.0 points (interquartile range, $6.0-10.0$ points), respectively. Elderly patients had lower-than-normal serum albumin levels (median, $3.4 \mathrm{~g} / \mathrm{dL}$ ). Regarding the presence of pressure ulcer risk factors in elderly patients, 38 were unable to reposition themselves in bed (69.1\%), 50 had urinary incontinence (90.9\%), and 43 had fecal incontinence (78.2\%).

\subsection{A Comparison between Elderly Patients and Healthy Young Adults}

A comparison of the six skin physiological indices between elderly patients and healthy young adults is presented in Figures 1-6. Boxplots represent the first quartile, median value, and their quartile, with lower and upper whiskers indicating the maximum and minimum excluded outliers, respectively, the mean value indicating the cross into the box, and points indicating outliers. Elderly patients had significantly higher epidermal water content at the sacrum than healthy young people $(p=0.025)$ (Figure 1$)$. Conversely, elderly patients had lower epidermal water content at both heels than in healthy young adults ( $p<$ 0.001 and 0.003 for the right and left heel, respectively). Both elderly patients and healthy young adults had an epidermal water content that was classified as very dry at all sites. Moreover, elderly patients had significantly lower TEWL across all sites than healthy young adults ( $p<0.001$ for all sites) (Figure 2). Both elderly patients and healthy young adults had very good or good TEWL at the sacrum and back. However, TEWL values in both heels were normal in elderly patients but poor in healthy young adults. Elderly patients had significantly higher skin erythema values at the back and sacrum than healthy young adults ( $p<0.001$ for both areas) (Figure 3 ), while both elderly patients and healthy young adults had minor skin erythema across all sites. Furthermore, elderly patients had lower skin elasticity at the back and sacrum ( $p<0.001$ for both areas) (Figure 4) and significantly higher skin surface temperature at all sites $(p<$ 0.001 for all sites) (Figure 5) compared to healthy young adults. The sacral and 
right heel skin was significantly thinner in elderly patients than in healthy young adults ( $p<0.001$ for the sacrum and $p=0.037$ for the right heel) (Figure 6). High statistical power was observed for the significant differences in skin elasticity and thickness (skin elasticity: back, 0.92; sacrum, 0.90; sacral skin thickness: $0.76)$.

Table 1. Demographic characteristics of elderly patients and healthy young adults.

\begin{tabular}{|c|c|c|c|c|c|}
\hline Variable & \multicolumn{2}{|c|}{$\begin{array}{l}\text { Elderly patients } \\
\qquad(\mathrm{n}=55)\end{array}$} & \multicolumn{2}{|c|}{$\begin{array}{l}\text { Healthy young adults } \\
\qquad(\mathrm{n}=25)\end{array}$} & \multirow[t]{2}{*}{$p$} \\
\hline Sex & & & & & \\
\hline Women, n (\%) & 32 & $(58.2)$ & 25 & (100) & \\
\hline Age, years & 85.0 & $(75.0-89.0)$ & 21.0 & $(20.5-22.0)$ & $<0.000^{\mathrm{a}}$ \\
\hline BMI, $\mathrm{kg} / \mathrm{m}^{2}$ & 20.0 & $(17.0-22.0)$ & 22.7 & $(17.0-24.0)$ & $<0.001^{\mathrm{a}}$ \\
\hline
\end{tabular}

${ }^{a}$ Mann-Whitney $U$ test. Data are presented as median (interquartile range). BMI, body mass index.

Table 2. Clinical characteristics and pressure ulcer risk in elderly patients.

\begin{tabular}{|c|c|c|}
\hline Variables & \multicolumn{2}{|c|}{$\begin{array}{l}\text { Elderly patients } \\
\qquad(\mathrm{n}=55)\end{array}$} \\
\hline \multicolumn{3}{|l|}{ Diagnosis (multiple answers) } \\
\hline Neoplasms, n (\%) & 4 & $(8.0)$ \\
\hline Endocrine, nutritional, and metabolic diseases, n (\%) & 12 & $(24.0)$ \\
\hline Dementia in Alzheimer disease, $\mathrm{n}(\%)$ & 14 & $(25.5)$ \\
\hline Extrapyramidal and movement disorders, n (\%) & 11 & $(20.0)$ \\
\hline Heart diseases, n (\%) & 15 & $(27.3)$ \\
\hline Cerebrovascular diseases, n (\%) & 38 & $(69.1)$ \\
\hline Respiratory diseases, n (\%) & 12 & $(21.8)$ \\
\hline \multicolumn{3}{|l|}{ Laboratory test } \\
\hline Albumin (g/dL), median (interquartile range) & 3.4 & $(3.1-3.7)$ \\
\hline Total protein $(\mathrm{g} / \mathrm{dL})$, median (interquartile range) & 6.8 & $(6.3-7.3)$ \\
\hline Red blood cell $\left(10^{6} / \mathrm{dL}\right)$, median (interquartile range) & 3.8 & $(3.2-4.2)$ \\
\hline Hemoglobin (g/dL), median (interquartile range) & 11.5 & $(10.4-13.4)$ \\
\hline Braden Scale total score, median (interquartile range) & 12.5 & $(9.0-15.0)$ \\
\hline Mini Nutritional Assessment, median (interquartile range) & 8.0 & $(6.0-10.0)$ \\
\hline \multicolumn{3}{|l|}{ Pressure ulcer risk factors } \\
\hline Repositioning individuals in bed, unable, n (\%) & 38 & $(69.1)$ \\
\hline Bony prominence, yes, n (\%) & 16 & $(29.1)$ \\
\hline Joint contracture, yes, n (\%) & 35 & $(63.6)$ \\
\hline Urinary incontinence, yes, $\mathrm{n}(\%)$ & 50 & $(90.9)$ \\
\hline Fecal incontinence, yes, $\mathrm{n}(\%)$ & 43 & $(78.2)$ \\
\hline Edema, yes, n (\%) & 24 & $(43.6)$ \\
\hline
\end{tabular}






Figure 1. Epidermal water content. ${ }^{a}$ Independent $t$-test; ${ }^{\mathrm{b}}$ Mann-Whitney $U$ test. AU, arbitrary units.

Transepidermal water loss (TEWL) $\left(\mathrm{g} / \mathrm{hm}^{2}\right)$

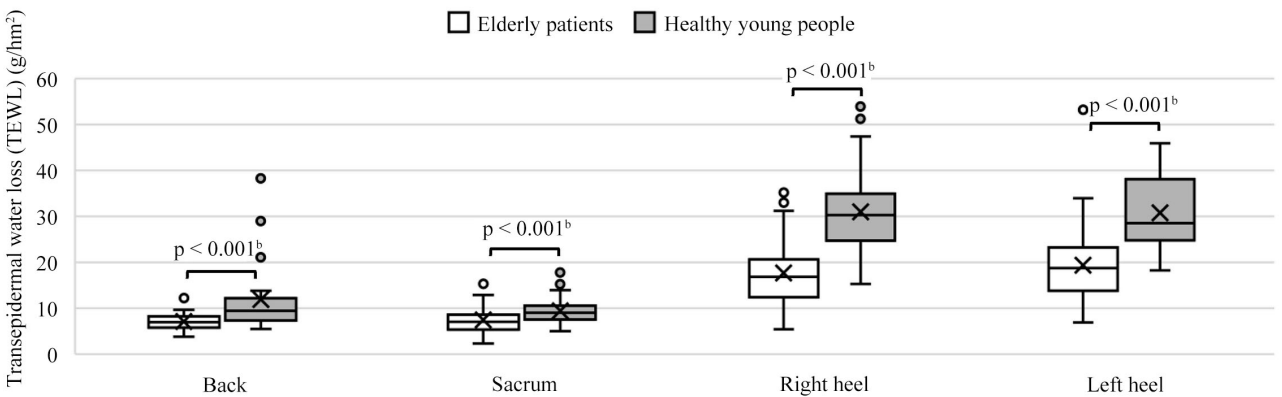

Figure 2. Transepidermal water loss (TEWL). ${ }^{\mathrm{b}} \mathrm{Mann}$-Whitney $U$ test. TEWL, transepidermal water loss.

Skin erythema $(\mathrm{AU})$

$\square$ Elderly patients $\square$ Healthy young people





Skin elasticity (AU)

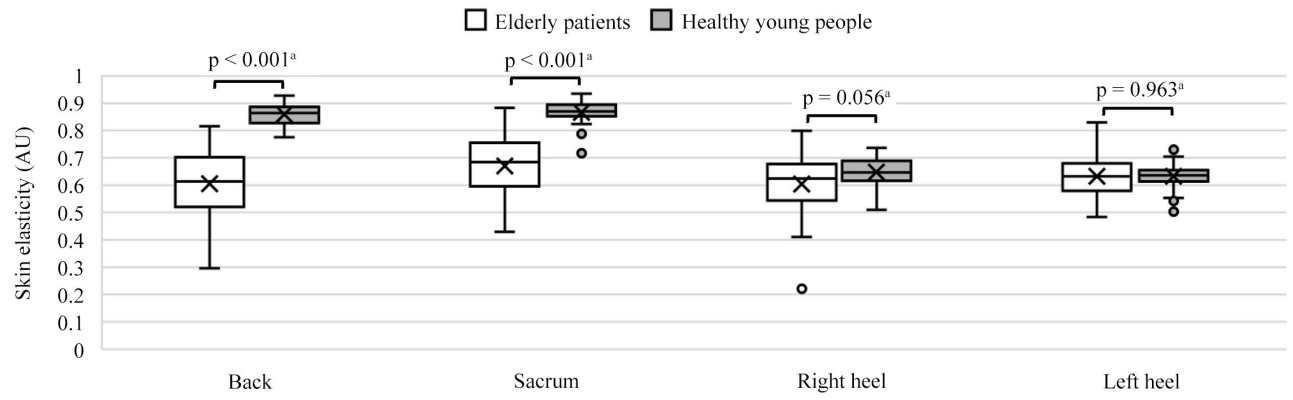

Figure 4. Skin elasticity. ${ }^{a}$ Independent $t$-test. AU, arbitrary units. 




Figure 5. Skin surface temperature. ${ }^{a}$ Independent $t$-test.

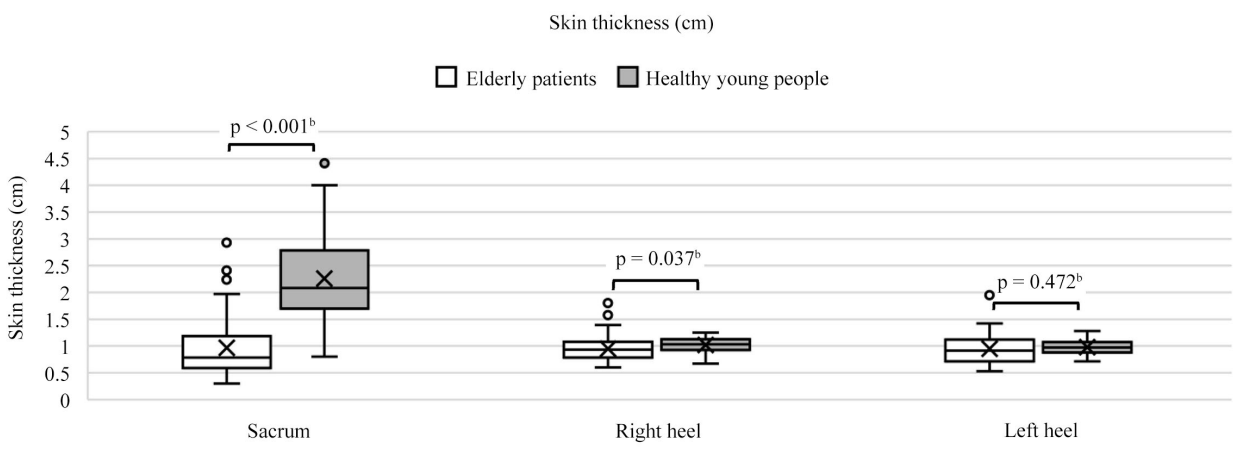

Figure 6. Skin thickness. ${ }^{\mathrm{b}}$ Mann-Whitney $U$ test.

\subsection{Relationship between Skin Physiological Indices and Demographic/Laboratory Data in Elderly Patients}

After examining the relationship between demographic/laboratory data and skin physiological indices (data not shown), our results found a moderate negative correlation between heel skin temperature and age (right heel, $\mathrm{r}=-0.451, p<$ 0.001 ; left heel, $\mathrm{r}=-0.541, p<0.001$ ), as well as a weak negative correlation between skin temperature at the back and sacrum and BMI (back, $\mathrm{r}=-0.394, p=$ 0.003 ; sacrum, $\mathrm{r}=-0.382, p=0.005)$. Moreover, weak positive correlations were observed between sacral erythema and age $(\mathrm{r}=0.319, p=0.025)$ and between sacral erythema and total protein level $(\mathrm{r}=-0.311, p=0.025)$. Moderate and weak positive correlations were observed between back $(\mathrm{r}=0.445, p<0.001)$ and sacral $(\mathrm{r}=0.273, p<0.045)$ skin elasticity and serum albumin levels, respectively. Conversely, a weak negative correlation was found between back skin elasticity and age $(\mathrm{r}=-0.355, p=0.009)$. Skin thickness and BMI showed a moderately positive correlation at all sites (sacrum, $\mathrm{r}=0.506, p<0.001$; right heel, $\mathrm{r}=0.482$, $p<0.001$; left heel, $\mathrm{r}=0.460, p<0.001$ ). Finally, sacral skin thickness and serum albumin levels showed a weak positive correlation $(\mathrm{r}=0.282, p=0.041)$. No other correlations were observed. The statistical power for moderate correlations between skin physiological indices and pressure ulcer risk in elderly patients ranged from 0.94 to 0.99 .

\section{Discussion}

The current study determined the skin physiological indices of sites predisposed 
to pressure ulcers in high-risk elderly patients. Notably, our findings showed very low epidermal water content at all sites, relatively good skin barrier function at all site predisposed to pressure ulcers in high-risk elderly patients, low sacral skin elasticity values, and thin sacral skin thickness.

\subsection{Epidermal Water Content}

Both elderly patients and healthy young adults had epidermal water content at all sites that was lower than the reference value of $50 \mathrm{AU}$, indicating very dry skin. Elderly patients, in particular, exhibited extremely low epidermal water content at both heels. However, no correlations were noted between epidermal water content at all sites and age, BMI, and laboratory test parameters in elderly patients. Although a previous study by $\mathrm{He}$ et al. [17] on intensive care unit patients found that lower epidermal water content was a risk factor for pressure ulcers, Sanada et al. [36] revealed that higher epidermal water content was associated with increased occurrence of pressure ulcers. Vulnerable skin conditions, such as excessive dryness or wetness, increase friction and shear, resulting in injuries to the skin and subcutaneous tissues. Moreover, skin dryness in elderly patients, especially at the heels, might increase the high risk of pressure ulcer formation.

\subsection{Transepidermal Water Loss}

Given that TEWL increases with dry skin due to the decrement of intercellular lipids, it has been the most reliable indicator of skin barrier function. Accordingly, our results found that elderly patients had maintained relatively good TEWL at sites predisposed to pressure ulcers despite having very dry skin. On the other hand, healthy young adults had good or very good TEWL at the back and sacrum but very poor TEWL at both heels. Nonetheless, reports have shown relatively high TEWL at the palm, sole, and forehead owing to eccrine sweat gland activity [13] [16]. As such, the high TEWL levels at both heels among healthy young adults may not indicate decreased skin barrier function but may instead be associated with age-dependent hyperhidrotic function.

\subsection{Skin Erythema}

Although elderly patients showed significantly higher back and sacral skin erythema values than healthy young adults, both elderly patients and healthy young adults exhibited minor skin erythema in all sites. Previous studies have shown that Iranians had a back skin erythema level of $331.94 \pm 62.23 \mathrm{AU}$ [16], whereas Swiss volunteers had a sacral erythema of $163.2 \pm 48.3 \mathrm{AU}$ [19], indicating differences in skin color among different races [13] [37]. We believe that the "minor erythema" measured in the current study might have been an overestimation related to the Mongolian skin color. Although most elderly patients included herein had urinary and fecal incontinence, we could not determine whether the higher level of skin erythema (>200 AU) in elderly patients indi- 
cated inflammation or stasis. However, we suppose that the minor erythema at the predisposed sites seen in elderly patients may be a race-dependent phenomenon.

\subsection{Skin Elasticity}

Elderly patients had significantly lower skin elasticity values at the back and sacral areas than healthy young adults. Another study also found that elderly individuals had lower skin elasticity than young individuals [38]. This may be attributed to the reduction in collagen synthesis and degeneration of the extracellular matrix that occur with increasing age, which promote decreased skin elasticity [9]. Notably, the current study found that serum albumin levels had a moderate positive correlation with back skin elasticity and a weak positive correlation with sacral skin elasticity, suggesting that skin elasticity in elderly patients might be affected by serum albumin levels, as well as aging.

\subsection{Skin Surface Temperature}

Our results found that elderly patients had significantly higher skin surface temperatures at all sites than healthy young adults. Nonetheless, the healthy young adults included herein exhibited back $\left(33.7^{\circ} \mathrm{C} \pm 1.0^{\circ} \mathrm{C}\right)$ and heel (right, $25.9^{\circ} \mathrm{C} \pm 2.6^{\circ} \mathrm{C}$; left, $25.8^{\circ} \mathrm{C} \pm 2.5^{\circ} \mathrm{C}$ ) temperatures that were similar to those of healthy 40 -year-old adults (spine, around $32^{\circ} \mathrm{C}$; foot arch, around $27.6^{\circ} \mathrm{C}$ ) [13]. Thus, the low skin temperatures among the healthy young adults cannot considered abnormal. Considering that most elderly patients included herein were bedridden and spent prolonged periods in bed with blankets, the differences in skin surface temperatures between elderly patients and healthy young adults were considered to have been caused by the impact of the living environment.

\subsection{Skin Thickness}

The current study found that elderly patients exhibited significantly lower sacral skin thickness than healthy young adults. Aging has been found to be accompanied by a decrease in the number of fibroblasts, which reduces the collagen and proteoglycan contents of the dermis, and fat cell atrophy in subcutaneous tissues. This, in turn, promotes the thinning of the dermis and subcutaneous tissue among elderly people. Additionally, a moderate positive correlation between sacral skin thickness and BMI was observed. Supporting our results, Schubert et al. [39] demonstrated that elderly patients with pressure ulcers had skin thinning at the sacral area and lower BMI. Therefore, skin thinning at predisposed sites in elderly patients is an important parameter when evaluating pressure ulcer risk. BMI, a well-known nutritional index, can be indicative of skin thickness. Notably, a significant difference in skin thickness had been observed between elderly patients and healthy young adults at the right but not left heel. However, heel skin thickness was measured from the calcaneal bone surface to the skin surface, which may carry significance given that adipose tissue thickness around the cal- 
caneus has been thought to have a minor relationship with total body fat. Nevertheless, the authors believe that neither aging nor BMI affected the skin thickness at both heels in high-risk elderly patients.

\subsection{Limitations and Implications for Clinical Practice}

Sime limitations of the current study include its small sample size, single-center cross-sectional design, and predominance of female participants due to convenience sampling. Therefore, our findings should not be generalized to other cohorts. However, we believe that determining skin physiological indices at common pressure ulcer sites in elderly Japanese patients with age-related diseases and malnutrition is of considerable significance. Larger, multi-center, and sex-balanced studies will therefore be needed in the future. Moreover, given that this study was performed between October and August, climate variations during this period may have influenced the measurements of skin surface temperature, epidermal water content, and TEWL.

The current study identified parameters that should be monitored in elderly Japanese patients at high risk for developing pressure ulcers based on those listed in several guidelines [40]. Assessing skin thickness and elasticity, as well as the patients' nutritional status, particularly BMI, is important when evaluating pressure ulcer risks at the sacral region. Meanwhile, assessing skin moisture is important when evaluating pressure ulcer risks at the heels.

\section{Conclusion}

The current study observed the following physiological skin characteristics of sites predisposed to pressure ulcer: 1) remarkably reduced epidermal water content in the heels; 2) decreased elasticity in the sacrum; and 3) reduced skin thickness in the sacrum. Relatively favorable values had been observed for skin temperature and TEWL value, even among bedridden elderly patients at high risk of pressure ulcer. The findings of the current study suggest that skin thickness and elasticity should be prioritized when evaluating pressure ulcer risk at sacral region among bedridden elderly Japanese patients. Moreover, skin moisture should be incorporated when evaluating pressure ulcer risk at the heels in the same patients.

\section{Acknowledgements}

The authors would like to express their gratitude to all participants for their contribution to this research, as well as to the staff of Shiragikuen Hospital, Tosa, Kochi, Japan for facilitating this study.

\section{Funding}

The design of the study; collection, analysis, and interpretation of data; and writing of the manuscript were supported by JSPS KAKENHI Grant Number JP $15 \mathrm{~K} 11813$ and $16 \mathrm{~K} 12263$. 


\section{Conflicts of Interest}

The authors declare no conflicts of interest regarding the publication of this paper.

\section{References}

[1] VanGilder, C., Lachenbruch, C., Algrim-Boyle, C. and Meyer, S. (2017) The International Pressure Ulcer Prevalence ${ }^{\mathrm{Tm}}$ Survey: 2006-2015: A 10-Year Pressure Injury Prevalence and Demographic Trend Analysis by Care Setting. Journal of Wound, Ostomy, and Continence Nursing. Official Publication of the Wound, Ostomy and Continence Nurses Society, 44, 20-28. https://doi.org/10.1097/WON.0000000000000292

[2] Sugama, J., Shido, K., Ishikawa, O., Sanada, H., Sato, A., Kaitani, T., Abe, M., Kawakami, S., Mitomi, Y., Oka, H. and Tanaka, K. (2008) Ryouyoubasyobetsu jyokusou yuubyouritsu jyokusou no bui jyuusyoudo (fukasa) [The Prevalence, Characteristics, Sites, and Severity of Pressure Ulcers According to the Facilities]. Japanese Journal of Pressure Ulcers, 10, 153-161. (In Japanese)

[3] Konya, C., Shido, K., Abe, M., Abe, Y., Iizaka, S., Shimada, K., Syoujyu, S., Tanaka, K., Higuchi, H. and Mizuki, T. (2018) Ryouyoubasyobetsu jijyuu kanren jyokusou to iryou kanren kikiappaku sousyou wo awaseta jyokusou no yuubyouritsu yuubyousya no tokutyou bui jyuusyoudo [The Prevalence, Characteristics, Sites, and Severity of Pressure Ulcers (Self-Weight-Related Pressure Ulcers and Medical-Device-Related Pressure Ulcers) According to the Facilities]. Japanese Journal of Pressure Ulcers, 20, 423-445. (In Japanese)

[4] Dealey, C., Posnett, J. and Walker, A. (2012) The Cost of Pressure Ulcers in the United Kingdom. Journal of Wound Care, 21, 261-264.

https://doi.org/10.12968/jowc.2012.21.6.261

[5] Sebba Tosta de Souza, D.M., Veiga, D.F., Santos, I.D., Abla, L.E., Juliano, Y. and Ferreira, L. (2015) Health-Related Quality of Life in Elderly Patients with Pressure Ulcers in Different Care Settings. Journal of Wound, Ostomy, and Continence Nursing: Official publication of the Wound, Ostomy and Continence Nurses Society, 42, 352-359. https://doi.org/10.1097/WON.0000000000000142

[6] Kohara, H., Ikeda, M., Inoue, M. and Morishita, S. (2017) A Survey of Home Care Patients Suffering from Pressure Ulcer in Kochi. Journal of Kochi Women's University Academy of Nursing, 42, 62-70. (In Japanese)

[7] Archer, D.F. (2012) Postmenopausal Skin and Estrogen. Gynecological Endocrinology, 28, 2-6. https://doi.org/10.3109/09513590.2012.705392

[8] Farage, M.A., Miller, K.W., Berardesca, E. and Maibach, H.I. (2009) Clinical Implications of Aging Skin: Cutaneous Disorders in the Elderly. American Journal of Clinical Dermatology, 10, 73-86. https://doi.org/10.2165/00128071-200910020-00001

[9] Yaar, M. (2006) Clinical and Histological Features of Intrinsic versus Extrinsic Skin Aging. In: Gilchrest, B.A. and Krutmann, J., Eds., Skin Aging, Springer, Heidelberg, 198. https://doi.org/10.1007/3-540-32953-6 2

[10] Doughty, D.B. and McNichol, L.L. (2015) General Concepts Related to Skin and Soft Tissue Injury Caused by Mechanical Factors. In: Doughty, D.B. and McNichol, L.L., Eds., Wound, Ostomy and Continence Nurses Society ${ }^{\circledR}$ Core Curriculum: Wound Management, Wolters Kluwer, Philadelphia, 273-279.

[11] Chang, A.L., Wong, J.W., Endo, J.O. and Norman, R.A. (2013) Geriatric Dermatol- 
ogy Review: Major Changes in Skin Function in Older Patients and Their Contribution to Common Clinical Challenges. Journal of the American Medical Directors Association, 14, 724-730. https://doi.org/10.1016/j.jamda.2013.02.014

[12] Kottner, J. and Beeckman, D. (2015) Incontinence-Associated Dermatitis and Pressure Ulcers in Geriatric Patients. Giornale Italiano di Dermatologia e Venereologia, 150, 717-729.

[13] Kleesz, P., Darlenski, R. and Fluhr, J.W. (2012) Full-Body Skin Mapping for Six Biophysical Parameters: Baseline Values at 16 Anatomical Sites in 125 Human Subjects. Skin Pharmacology and Physiology, 25, 25-33.

https://doi.org/10.1159/000330721

[14] Yusuf, S., Okuwa, M., Shigeta, Y., Dai, M., Iuchi, T., Rahman, S., Usman, A., Kasim, S., Sugama, J., Nakatani, T. and Sanada, H. (2015) Microclimate and Development of Pressure Ulcers and Superficial Skin Changes. International Wound Journal, 12, 40-46. https://doi.org/10.1111/iwj.12048

[15] Fiedler, M., Gerhardt, L.C., Derler, S., Bischofberger, G., Hürny, C. and Münzer, T. (2012) Assessment of Biophysical Skin Properties at Different Body Sites in Hospitalized Old Patients: Results of a Pilot Study. Gerontology, 58, 513-517. https://doi.org/10.1159/000336623

[16] Firooz, A., Sadr, B., Babakoohi, S., Sarraf-Yazdy, M., Fanian, F., Kazerouni-Timsar, A., Nassiri-Kashani, M., Naghizadeh, M.M. and Dowlati, Y. (2012) Variation of Biophysical Parameters of the Skin with Age, Gender, and Body Region. Thescientificworldjournal, 2012, Article ID: 386936. https://doi.org/10.1100/2012/386936

[17] He, M., Tang, A., Ge, X. and Zheng, J. (2016) Pressure Ulcers in the Intensive Care Unit: An Analysis of Skin Barrier Risk Factors. Advances in Skin \& Wound Care, 29, 493-498. https://doi.org/10.1097/01.ASW.0000494779.66288.c9

[18] Nagase, S., Ogai, K., Urai, T., Shibata, K., Matsubara, E., Mukai, K., Matsue, M., Mori, Y., Aoki, M., Arisandi, D., Sugama, J. and Okamoto, S. (2020) Distinct Skin Microbiome and Skin Physiological Functions between Bedridden Older Patients and Healthy People: A Single-Center Study in Japan. Frontiers in Medicine, 7, 101. https://doi.org/10.3389/fmed.2020.00101

[19] Scheel-Sailer, A., Frotzler, A., Mueller, G., Annaheim, S., Rossi, R.M. and Derler, S. (2015) Challenges to Measure Hydration, Redness, Elasticity and Perfusion in the Unloaded Sacral Region of Healthy Persons after Supine Position. Journal of Tissue Viability, 24, 62-70. https://doi.org/10.1016/j.jtv.2015.03.002

[20] Yalcin, E., Akyuz, M., Onder, B., Unalan, H. and Degirmenci, I. (2013) Skin Thickness on Bony Prominences Measured by Ultrasonography in Patients with Spinal Cord Injury. Journal of Spinal Cord Medicine, 36, 225-230. https://doi.org/10.1179/2045772312Y.0000000088

[21] Bergstrom, N., Braden, B.J., Laguzza, A. and Holman, V. (1987) The Braden Scale for Predicting Pressure Sore Risk. Nursing Research, 36, 205-210. https://doi.org/10.1097/00006199-198707000-00002

[22] Berardesca, E. (1997) Eemco Guidance for the Assessment of Stratum Corneum Hydration: Electrical Methods. Skin Research and Technology, 3, 126-132.

https://doi.org/10.1111/j.1600-0846.1997.tb00174.x

[23] Heinrich, U., Koop, U., Leneveu-Duchemin, M.C., Osterrieder, K., Bielfeldt, S., Chkarnat, C., Degwert, J., Hantschel, D., Jaspers, S., Nissen, H.P., Rohr, M., Schneider, G. and Tronnier, H. (2003) Multicentre Comparison of Skin Hydration in Terms of Physical-, Physiological- and Product-Dependent Parameters by the Capacitive Method (Corneometer Cm 825). International Journal of Cosmetic 
Science, 25, 45-53. https://doi.org/10.1046/j.1467-2494.2003.00172.x

[24] Barel, A.O. and Clarys, P. (1995) Study of the Stratum Corneum Barrier Function by Transepidermal Water Loss Measurements: Comparison between Two Commercial Instruments: Evaporimeter and Tewameter. Skin Pharmacology, 8, 186-195. https://doi.org/10.1159/000211345

[25] Bornkessel, A., Flach, M., Arens-Corell, M., Elsner, P. and Fluhr, J.W. (2005) Functional Assessment of a Washing Emulsion for Sensitive Skin: Mild Impairment of Stratum Corneum Hydration, Ph, Barrier Function, Lipid Content, Integrity and Cohesion in a Controlled Washing Test. Skin Research and Technology, 11, 53-60. https://doi.org/10.1111/j.1600-0846.2005.00091.x

[26] Clarys, P., Alewaeters, K., Lambrecht, R. and Barel, A.O. (2000) Skin Color Measurements: Comparison between Three Instruments: The Chromameter(R), the Dermaspectrometer(R) and the Mexameter(R). Skin Research and Technology, 6, 230-238. https://doi.org/10.1034/j.1600-0846.2000.006004230.x

[27] Shin, J.W., Lee, D.H., Choi, S.Y., Na, J.I., Park, K.C., Youn, S.W. and Huh, C.H. (2011) Objective and Non-Invasive Evaluation of Photorejuvenation Effect with Intense Pulsed Light Treatment in Asian Skin. Journal of the European Academy of Dermatology and Venereology, 25, 516-522.

https://doi.org/10.1111/j.1468-3083.2010.03815.x

[28] Everett, J.S. and Sommers, M.S. (2013) Skin Viscoelasticity: Physiologic Mechanisms, Measurement Issues, and Application to Nursing Science. Biological Research for Nursing, 15, 338-346. https://doi.org/10.1177/1099800411434151

[29] Gerhardt, L.C., Lenz, A., Spencer, N.D., Münzer, T. and Derler, S. (2009) Skin-Textile Friction and Skin Elasticity in Young and Aged Persons. Skin Research and Technology, 15, 288-298. https://doi.org/10.1111/j.1600-0846.2009.00363.x

[30] Braden, B. and Bergstrom, N. (1987) A Conceptual Schema for the Study of the Etiology of Pressure Sores. Rehabilitation Nursing, 12, 8-12. https://doi.org/10.1002/j.2048-7940.1987.tb00541.x

[31] Ayello, E.A. and Braden, B. (2002) How and Why to Do Pressure Ulcer Risk Assessment. Advances in Skin \& Wound Care, 15, 125-131.

https://doi.org/10.1097/00129334-200205000-00008

[32] Kagansky, N., Berner, Y., Koren-Morag, N., Perelman, L., Knobler, H. and Levy, S. (2005) Poor Nutritional Habits Are Predictors of Poor Outcome in Very Old Hospitalized Patients. American Journal of Clinical Nutrition, 82, 784-791. https://doi.org/10.1093/ajcn/82.4.784

[33] Yatabe, M.S., Taguchi, F., Ishida, I., Sato, A., Kameda, T., Ueno, S., Takano, K., Watanabe, T., Sanada, H. and Yatabe, J. (2013) Mini Nutritional Assessment as a Useful Method of Predicting the Development of Pressure Ulcers in Elderly Inpatients. Journal of the American Geriatrics Society, 61, 1698-1704.

https://doi.org/10.1111/jgs.12455

[34] Faul, F., Erdfelder, E., Lang, A.-G. and Buchner, A. (2007) G*Power 3: A Flexible Statistical Power Analysis Program for the Social, Behavioral, and Biomedical Sciences. Behavior Research Methods, 39, 175-191.

https://doi.org/10.3758/BF03193146

[35] Faul, F., Erdfelder, E., Buchner, A. and Lang, A.-G. (2009) Statistical Power Analyses Using G*Power 3.1: Tests for Correlation and Regression Analyses. Behavior Research Methods, 41, 1149-1160. https://doi.org/10.3758/BRM.41.4.1149

[36] Sanada, H., Sugama, J., Kitagawa, A., Thigpen, B., Kinosita, S. and Murayama, S. (2007) Risk Factors in the Development of Pressure Ulcers in an Intensive Care 
Unit in Pontianak, Indonesia. International Wound Journal, 4, 208-215.

https://doi.org/10.1111/j.1742-481X.2007.00315.x

[37] Fullerton, A., Fischer, T., Lahti, A., Wilhelm, K.P., Takiwaki, H. and Serup, J. (1996) Guidelines for Measurement of Skin Colour and Erythema. A Report from the Standardization Group of the European Society of Contact Dermatitis. Contact Dermatitis, 35, 1-10. https://doi.org/10.1111/j.1600-0536.1996.tb02258.x

[38] Ryu, H.S., Joo, Y.H., Kim, S.O., Park, K.C. and Youn, S.W. (2008) Influence of Age and Regional Differences on Skin Elasticity as Measured by the Cutometer. Skin Research and Technology, 14, 354-358.

https://doi.org/10.1111/j.1600-0846.2008.00302.x

[39] Schubert, V., Ohlsson, K. and Stevens, U. (1992) Reduced Tissue Thickness over the Sacrum as a Risk Factor for Pressure Sores. Journal of Tissue Viability, 2, 82-86. https://doi.org/10.1016/S0965-206X(14)80146-0

[40] National Pressure Ulcer Advisory Panel, European Pressure Ulcer Advisory Panel and Pan Pacific Pressure Injury Alliance (2014) Prevention and Treatment of Pressure Ulcers: Quick Reference Guide. Cambridge Media, Osborne Park, 12-13. 